\title{
First-phase insulin response in young healthy children at genetic and immunological risk for Type I diabetes
}

\author{
P. Keskinen ${ }^{1,2,3}$, S. Korhonen ${ }^{1,4}$, A. Kupila ${ }^{1,2}$, R. Veijola ${ }^{1,4}$, S. Erkkilä ${ }^{1,2}$, H. Savolainen ${ }^{1,2}$, P. Arvilommi ${ }^{1,2}$, \\ T. Simell ${ }^{1,2}$, J. Ilonen ${ }^{1,5}$, M. Knip ${ }^{1,3,6}$, O. Simell ${ }^{1,2}$ \\ 1 The JDRF Center for Prevention of Type I Diabetes in Finland \\ ${ }^{2}$ Department of Pediatrics, University of Turku, Turku, Finland \\ ${ }^{3}$ Department of Pediatrics, Medical School, University of Tampere, and Tampere University Hospital, Tampere, Finland \\ ${ }^{4}$ Department of Pediatrics, University of Oulu, Oulu, Finland \\ ${ }^{5}$ Department of Virology, University of Turku, Turku, Finland \\ ${ }^{6}$ Hospital for Children and Adolescents, University of Helsinki, Helsinki, Finland
}

\section{Abstract}

Aims/hypothesis. A reduced first-phase insulin response to intravenous glucose is perceived as a sign of far-advanced deterioration of beta-cell function during the development of Type I (insulin-dependent) diabetes mellitus, but data on insulin responses at the onset of diabetes-related autoimmunity are lacking. We studied the first-phase insulin responses of small children soon after observed seroconversion to autoantibody positivity.

Methods. In the Type I Diabetes Prediction and Prevention Study newborn infants are screened for HLADQB1-associated genetic risk for Type I diabetes and those with increased risk are followed-up for the emergence of islet-cell antibodies. If antibodies are detected, autoantibodies to three other antigens (insulin, GAD65 and IA-2) are also measured. To measure first-phase insulin responses, intravenous glucose tolerance tests were carried out in 52 (1 to 5-year-old) children who had recently seroconverted to islet-cell antibody positivity.
Results. The first-phase insulin response was subnor$\mathrm{mal}\left(<38 \mathrm{mU} / \mathrm{l}\right.$, the $5^{\text {th }}$ percentile of insulin responses of 20 islet-cell antibody negative healthy children at this age) in 22 of the 52 children (42\%). Stepwise multiregression analysis showed that islet-cell antibody greater than $20 \mathrm{JDFU}(p=0.0005)$, insulin autoantibodies $(p=0.0009)$ and an increasing number of positive autoantibodies $(p=0.0011)$ were independent predictors of low first-phase insulin response.

Conclusion/interpretation. A decreased first-phase insulin response could be an early phenomenon in the course of prediabetes in young children, implying a rapid autoimmune destruction or loss of function of beta cells as well as possible metabolic compensation mechanisms, since 11 out of the 22 high risk children remain nondiabetic for a considerable period of time despite low insulin responses. [Diabetologia (2002) 45:1639-1648]

Keywords Autoantibodies, HLA risk markers, insulin secretion, prediabetic state, Type I diabetes.
Received: 11 January 2002 / Revised: 30 July 2002

Published online: 30 October 2002

(C) Springer-Verlag 2002

Corresponding author: Dr. P. Keskinen, The JDRF Center for Prevention of Type I Diabetes in Finland. E-mail: paivi.keskinen@uta.fi

Abbreviations: DIPP, Type I Diabetes Prediction and Prevention project; FPIR, first-phase insulin response; GAD65, 65 kilodalton isoform of glutamic acid decarboxylase; GADA, antibodies to GAD65; IAA, insulin autoantibodies; IA-2A, antibodies to the protein tyrosine phosphatase related IA-2 molecule; ICA, islet-cell antibodies; JDFU, Juvenile Diabetes Foundation units; RU, relative units.
An autoimmune attack governed by cells of T-cell lineages begins to destroy insulin-producing pancreatic beta cells at a poorly defined time point, as little is known about the course of decline in beta-cell function during prediabetes. The first-phase insulin response (FPIR) in an intravenous glucose tolerance test (IVGTT), due to discharge of the contents of a readily releasable pool of insulin-containing granules docked to the plasma membrane of beta cells [1], is probably the best currently available in vivo method for the assessment of the insulin-secretory capacity of the beta cells $[2,3]$. A release stimulus caused by glucose is clearly more sensitive in detecting early alterations in insulin secretion than that induced by other stimuli [4]. 
As a decreased FPIR value has been regarded as a late sign of beta-cell dysfunction $[5,6,7,8,9]$ associated with a high risk of diabetes development in the near future, it has been expected to be a measure poorly suited for estimation of the risk or prediction of the time of onset of the disease in the early phases of autoimmunity $[10,11]$. However, interpretation of the FPIR data obtained previously during the course of prediabetes is difficult because of the wide age range of the subjects studied and the heterogeneity of the stage of their prediabetes, due to the unknown duration of the period when the subjects had had circulating diabetes-associated autoantibodies. Consequently, the sensitivity, specificity and predictive value of FPIR in diabetes prediction and the time scale of the FPIR loss before the onset of clinical Type I diabetes have remained poorly defined $[5,6,7,11,12,13,14]$.

The Type I Diabetes Prediction and Prevention project (DIPP), launched several years ago in three university hospitals in Finland, is a prospective, populationbased study aimed at recognition of the genetically diabetes-prone individuals at birth $[15,16]$. Those at genetic risk are closely observed for the emergence of immunological signs of prediabetes and progression towards clinical disease. The capacity of beta cells to secrete insulin is evaluated by sequential IVGTTs in children who seroconvert to autoantibody positivity, and the children with permanent seropositivity are randomized into a placebo-controlled, double-blind prevention trial, which evaluates the efficacy of immunomodulation by intranasally applied insulin in diabetes prevention. In this study, we measured FPIRs as soon as practically possible in the first 52 DIPP children who seroconverted to islet-cell autoantibody (ICA) positivity during prospective follow-up, and whose parents gave informed consent for the study. Thus, for the first time, the time of seroconversion, assumed to be a firm sign of the initiation of the autoimmune processes, is known in the subjects studied.

\section{Subjects and methods}

The DIPP protocol. The Finnish Type I Diabetes Prediction and Prevention project, launched in 1994, now runs in three centres in Finland (the University Hospitals of Turku, Oulu and Tampere) [16]. Children born in these hospitals are screened for critical diabetes-associated HLA-DQB1 alleles at birth [17], and those with an increased genetic risk (the index children; $\sim 15 \%$ of the birth cohort) are invited to be observed for the emergence of diabetes-associated autoantibodies. Assessment of the genetic diabetes risk and immunological follow-up are offered also to older siblings of the index children. A blood sample for the genetic analysis is usually drawn from the sibling at the index child's first follow-up visit, and regular follow-up is initiated if the sibling carries a diabetes risk-associated genotype.

Antibodies are measured in serum at the ages of 3 and 6 months, then at 3-month (in Turku) or 6-month (in Oulu and Tampere) intervals until the age of 2 years, and thereafter at 6-month or 12-month intervals, respectively, up to the age of 15 years. ICA are used as the primary screening tool for betacell autoimmunity. If ICA are detected, autoantibodies against the $65 \mathrm{kD}$ isoform of glutamic acid decarboxylase (GADA), insulin (IAA) and the protein tyrosine phosphatase related IA-2 molecule (IA-2A) are also measured in all samples obtained from the child before seroconversion to ICA positivity (stored at $-70^{\circ} \mathrm{C}$ ) and in all subsequent samples, drawn from the ICA-positive children at 3-month intervals. An IVGTT is carried out in the autoantibody positive children at 3- to 12-month intervals. The DIPP project includes an intervention arm where currently the efficacy of intranasal insulin in the prevention of clinical diabetes is being studied in children with permanent autoantibody positivity, using a double-blind randomized study design.

The ethics committees of the participating hospitals and universities have approved the study. Separate informed consents were obtained from the parents before genetic screening of the newborn infant, onset of immunological follow-up, and randomization of the child to the prevention trial.

Genetic screening of the risk for Type I diabetes. HLA-DQB1 alleles $* 02, * 0301, * 0302, * 0602$ and $* 0603$ were identified using a semi-automated technology [17, 18]. Briefly, informative DNA sequences were PCR-amplified directly from cord blood spots dried on filter paper, amplified gene sequences were hybridized in solution with allele-specific, lanthanide chelate-labelled oligonucleotide probes, and the hybridization products were measured using time-resolved fluorometry (VICTOR fluorometer, Perkin-Elmer Life Sciences-Wallac, Turku, Finland).

Subjects with the HLA-DQB1 genotypes *02/*0302 and $* 0302 / x(x$ not $* 02, * 0301, * 0602$ or $* 0603$ ) were selected to follow-up. Children with the $* 02 / * 0302$ genotype were categorised into the group with high genetic risk (risk of diabetes before the age of 15 years about $8 \%$ ), and those with the $* 0302 / x$ genotype into the group with moderate genetic risk (risk $2-3 \%$ ). The risk of Type I diabetes before the age of 20 years is close to $0.7 \%$ in the background population [19].

Subjects in this study. We carried out IVGTTs in children who seroconverted to ICA positivity (at least one ICA positive sample after a minimum of one ICA negative sample after birth) and were 12 months of age or older, as soon as practically possible after the observed seroconversion. First-phase insulin responses from the very first IVGTT successfully carried out for each child after the seroconversion but before the onset of intervention therapy (i.e., nasal insulin or placebo spray) were included in this analysis.

First-phase insulin responses were obtained from 52 IVGTTs carried out in 48 index children and four siblings (Table 1). On three occasions the first IVGTT failed but the test was repeated successfully after 2 to 7 months. The age range of the children (mean \pm SD) at the time of the first IVGTT was 1.2 to 4.5 years $(2.5 \pm 1.1$ years), and at the time of the first serum sample containing detectable titres of ICA 0.5 to 4.3 years $(1.9 \pm 1.1$ years $)$. The time from the first ICA seropositive sample to the first IVGTT varied from 0.2 to 0.9 years $(0.6 \pm 0.2$ years $)$. A majority $(n=28 ; 54 \%)$ of the children were female. Seventeen children $(32.7 \%$; 6 boys and 11 girls) belonged to the group with high genetic risk and 35 children (67.3\%; 18 boys and 17 girls) to the group with moderate genetic risk. The body mass indexes ranged from 13.4 to $19.2 \mathrm{~kg} / \mathrm{m}^{2}\left(16.2 \pm 1.4 \mathrm{~kg} / \mathrm{m}^{2}\right.$; mean \pm SD) and that of weightfor-height from $-18 \%$ to $+18 \%(-2 \% \pm 8 \%)$ on the growth curves of healthy Finnish children. Weight-for-height exceeding $+20 \%$ is considered as overweight; thus, there were no 
Table 1. Data on the study children

\begin{tabular}{|c|c|c|c|c|c|c|c|c|c|c|c|c|c|}
\hline Code & $\begin{array}{l}\text { Age } \\
\text { (years) }\end{array}$ & $\begin{array}{l}\text { HLA- } \\
\text { DQB1 } \\
\text { genotype }\end{array}$ & Sex & $\begin{array}{l}\text { Weight } \\
\text { (kg) }\end{array}$ & $\begin{array}{l}\mathrm{BMI} \\
\left(\mathrm{kg} / \mathrm{m}^{2}\right)\end{array}$ & $\begin{array}{l}\text { Weight- } \\
\text { for-height } \\
(\%)\end{array}$ & $\begin{array}{l}\text { ICA } \\
\geq 20 \\
\text { JDFU }=+ \\
<20 \\
\text { JDFU }=-\end{array}$ & IAA & GADA & IA-2A & $\begin{array}{l}\text { FPIR } \\
(\mathrm{mU} / \mathrm{l})\end{array}$ & $\begin{array}{l}\text { AUC } \\
(0-10 \mathrm{~min}) \\
\left(\mathrm{mU} / \mathrm{l}^{-1}\right. \\
\left.10 \mathrm{~min}^{-1}\right)\end{array}$ & $\begin{array}{l}\text { Type I } \\
\text { diabetes } \\
\text { by May } 1 \\
2001\end{array}$ \\
\hline $162 \mathrm{~A}$ & 1.3 & 302 & $\mathrm{~m}$ & 11.1 & 16.9 & -4 & + & + & - & - & 23 & 106 & yes \\
\hline $272 \mathrm{~A}$ & 4.5 & 302 & $\mathrm{~m}$ & 18.9 & 15.8 & +2 & + & + & - & + & 35 & 135 & no \\
\hline $476 \mathrm{~A}$ & 1.5 & 302 & $\mathrm{f}$ & 11.2 & 17.4 & 0 & - & - & - & - & 48 & 175 & no \\
\hline $515 \mathrm{~A}$ & 4.5 & 302 & $\mathrm{~m}$ & 14.3 & 14.3 & -10 & - & - & - & - & 28 & 173 & no \\
\hline $572 \mathrm{~A}$ & 4.5 & $302 / 02$ & $\mathrm{~m}$ & 19.7 & 15.9 & +3 & - & - & - & - & 147 & 605 & no \\
\hline $579 A$ & 1.7 & 302 & $\mathrm{f}$ & 12.0 & 18.5 & +7 & - & + & - & - & 92 & 339 & no \\
\hline $630 \mathrm{~A}$ & 4.5 & $302 / 02$ & f & 22.8 & 18.2 & +16 & + & + & + & - & 39 & 159 & no \\
\hline $771 \mathrm{~A}$ & 2.7 & $302 / 02$ & f & 15.6 & 18.2 & +12 & + & + & + & + & 42 & 171 & no \\
\hline $1883 \mathrm{~A}$ & 2.2 & 302 & $\mathrm{~m}$ & 12.8 & 16.5 & -1 & - & - & - & - & 63 & 257 & no \\
\hline $2176 \mathrm{~A}$ & 1.3 & $302 / 02$ & $\mathrm{~m}$ & 11.7 & 18.4 & +4 & + & + & + & + & 20 & 95 & yes \\
\hline $2292 \mathrm{C}$ & 4.3 & $302 / 02$ & f & 16.0 & 14.6 & -7 & - & - & - & - & 56 & 209 & no \\
\hline $2532 \mathrm{~A}$ & 4.3 & $302 / 02$ & $\mathrm{~m}$ & 14.9 & 14.3 & -9 & - & - & - & - & 135 & 479 & no \\
\hline $3143 \mathrm{~A}$ & 2.6 & 302 & $\mathrm{~m}$ & 18.6 & 19.2 & +18 & - & - & - & - & 218 & 844 & no \\
\hline 3649A & 1.7 & 302 & $\mathrm{~m}$ & 11.8 & 16.1 & -6 & - & + & + & - & 43 & 187 & no \\
\hline $3688 \mathrm{~A}$ & 1.8 & $302 / 02$ & $\mathrm{f}$ & 10.7 & 15.0 & -11 & + & + & + & + & 31 & 146 & no \\
\hline $3755 \mathrm{~A}$ & 1.7 & 302 & $\mathrm{~m}$ & 11.5 & 16.7 & -4 & + & + & + & + & 50 & 194 & no \\
\hline $3836 \mathrm{~A}$ & 3.3 & 302 & $\mathrm{~m}$ & 15.2 & 15.0 & -6 & - & - & - & - & 33 & 136 & no \\
\hline $3860 \mathrm{C}$ & 3.7 & 302 & $\mathrm{f}$ & 21.8 & 18.3 & +17 & - & - & - & - & 95 & 401 & no \\
\hline 3899A & 1.2 & $302 / 02$ & $\mathrm{~m}$ & 12.2 & 18.1 & +4 & + & + & + & + & 16 & 76 & yes \\
\hline $4028 \mathrm{~A}$ & 3.6 & 302 & $\mathrm{~m}$ & 13.0 & 14.1 & -14 & - & - & - & - & 72 & 269 & no \\
\hline $4233 \mathrm{~A}$ & 3.8 & $302 / 02$ & $\mathrm{~m}$ & 14.2 & 15.7 & -4 & + & + & + & + & 69 & 285 & no \\
\hline $4369 \mathrm{~A}$ & 2.0 & 302 & $\mathrm{f}$ & 11.8 & 17.1 & 0 & - & - & - & - & 43 & 156 & no \\
\hline $4476 \mathrm{~A}$ & 3.5 & $302 / 02$ & f & 16.3 & 14.9 & -6 & - & - & - & - & 28 & 119 & no \\
\hline $4548 \mathrm{~B}$ & 4.2 & 302 & $\mathrm{~m}$ & 16.0 & 15.3 & -4 & - & - & - & - & 95 & 380 & no \\
\hline $5207 \mathrm{~A}$ & 1.8 & 302 & $\mathrm{~m}$ & 15.0 & 16.1 & -2 & + & + & - & - & 46 & 252 & yes \\
\hline $5281 \mathrm{~A}$ & 1.7 & 302 & $\mathrm{f}$ & 12.1 & 16.7 & -2 & - & - & - & - & 49 & 218 & no \\
\hline 5679A & 2.4 & $302 / 02$ & $\mathrm{~m}$ & 15.2 & 16.5 & +1 & - & - & - & - & 50 & - & no \\
\hline $5948 \mathrm{~A}$ & 3.2 & $302 / 02$ & $\mathrm{f}$ & 15.9 & 16.2 & +2 & - & + & + & - & 32 & 143 & no \\
\hline $6015 \mathrm{~A}$ & 2.3 & 302 & $\mathrm{~m}$ & 16.3 & 18.6 & +13 & - & - & - & - & 26 & 226 & no \\
\hline 6031A & 2.1 & $302 / 02$ & $\mathrm{f}$ & 13.3 & 15.1 & -7 & - & + & + & - & 30 & 114 & yes \\
\hline $6753 \mathrm{~A}$ & 2.7 & 302 & $\mathrm{~m}$ & 15.1 & 15.5 & -4 & - & + & - & + & 258 & 1005 & no \\
\hline $6905 \mathrm{~A}$ & 2.3 & 302 & f & 10.6 & 13.6 & -18 & - & - & - & + & 97 & 361 & no \\
\hline $6935 \mathrm{~A}$ & 1.2 & $302 / 02$ & f & 9.6 & 14.7 & -15 & + & + & + & + & 7 & 44 & yes \\
\hline 7801A & 2.2 & 302 & f & 11.7 & 15.5 & -8 & + & + & + & - & 13 & 74 & yes \\
\hline 7801B & 4.4 & 302 & f & 17.8 & 14.8 & -4 & + & + & + & + & 28 & 126 & no \\
\hline 8069A & 1.3 & $302 / 02$ & f & 11.2 & 17.5 & +6 & + & + & + & + & 12 & 59 & yes \\
\hline 8195A & 1.7 & $302 / 02$ & f & 13.0 & 16.0 & -1 & + & + & + & - & 15 & 67 & no \\
\hline $8224 \mathrm{~A}$ & 1.8 & 302 & f & 11.3 & 16.4 & -4 & - & - & - & - & 68 & 199 & no \\
\hline $9451 \mathrm{~A}$ & 2.4 & 302 & f & 11.6 & 15.3 & -8 & - & - & - & - & 105 & 393 & no \\
\hline $10414 \mathrm{~A}$ & 1.8 & $302 / 02$ & f & 11.5 & 15.3 & -9 & + & + & + & - & 21 & 87 & no \\
\hline $12543 \mathrm{~A}$ & 1.5 & 302 & $\mathrm{~m}$ & 12.3 & 17.0 & -2 & + & - & - & - & 39 & 146 & no \\
\hline $30303 \mathrm{~A}$ & 2.5 & 302 & f & 11.5 & 14.1 & +4 & + & + & + & - & 187 & 668 & no \\
\hline $30786 \mathrm{~A}$ & 2.1 & 302 & $\mathrm{~m}$ & 13.5 & 17.3 & +3 & - & + & + & + & 9 & 68 & no \\
\hline $31537 \mathrm{~A}$ & 2.3 & 302 & $\mathrm{f}$ & 12.7 & 17.6 & +4 & - & + & + & - & 73 & 285 & no \\
\hline $31875 \mathrm{~A}$ & 1.9 & 302 & $\mathrm{~m}$ & 13 & 15.9 & -6 & + & + & - & + & 12 & 62 & yes \\
\hline $35006 \mathrm{~A}$ & 2.4 & 302 & f & 12 & 13.4 & -16 & + & + & + & + & 77 & 249 & no \\
\hline $35160 \mathrm{~A}$ & 1.6 & 302 & f & 11 & 17.2 & 0 & + & + & + & + & 30 & 127 & yes \\
\hline $35386 \mathrm{~A}$ & 1.5 & 302 & $\mathrm{~m}$ & 10.5 & 14.9 & -14 & + & + & + & + & 15 & 75 & yes \\
\hline $36280 \mathrm{~A}$ & 1.4 & 302 & f & 10.2 & 15.3 & -11 & + & + & - & - & 22 & 108 & yes \\
\hline $36584 \mathrm{~A}$ & 2 & 302 & f & 11.3 & 15.6 & -7 & + & + & + & + & 48 & 185 & yes \\
\hline $36809 \mathrm{~A}$ & 2 & 302 & $\mathrm{~m}$ & 12.5 & 16.4 & -4 & + & - & - & + & 52 & 234 & no \\
\hline $38521 \mathrm{~A}$ & 1.7 & 302 & $\mathrm{f}$ & 13.7 & 17.9 & +7 & + & + & + & - & 39 & - & no \\
\hline
\end{tabular}

Data refer to values measured at the time of the intravenous glucose tolerance test. All children had a detectable amount $(>2.5 \mathrm{JDFU})$ of ICA 
overweight children in the study group. Five children had a first-degree relative with Type I diabetes. As their data showed no apparent differences from the data of the children without diabetes in the family, the data were analysed together. For calculation of FPIRs in healthy, ICA negative small children, preliminary results obtained from a separate, ongoing study (Korhonen et al., unpublished) were used. The 20 control children of normal weight, whose FPIR values were used as reference, were 1.3 to 4.9 years of age.

Autoantibody assays. Islet cell antibodies were analysed in Juvenile Diabetes Foundation units (JDFU) using a standard indirect immunofluorescence assay on a section of frozen human pancreas obtained from a blood group $\mathrm{O}$ donor and endpoint dilution titres [20]. The detection limit of the assay was 2.5 JDFU. Our laboratory had a sensitivity of $100 \%$ and a specificity of $98 \%$ in the recent round of the International Workshop on the Standardization of the ICA Assay.

Insulin autoantibodies were measured by a radioligand assay in a microplate format using a modification of a described method $[21,22]$. The cut-off limit for IAA positivity was set at the $99^{\text {th }}$ percentile in 371 non-diabetic Finnish subjects, that is, at 1.56 relative units (RU). The disease sensitivity of this assay was $35 \%$ and the disease specificity $100 \%$ based on 140 samples included in the 1995 Multiple Autoantibody Workshop [23].

Autoantibodies to GAD65 were measured using a radioligand assay as described [24]. The results were expressed in RU based on a standard curve run on each plate. The cut-off limit for positivity was $5.36 \mathrm{RU}$, representing the $99^{\text {th }}$ percentile in a group of 373 healthy children. The disease sensitivity of the assay was $69 \%$ and the specificity $100 \%$, based on the 140 samples included in the Multiple Autoantibody Workshop [23].

Autoantibodies to IA-2 were measured using a modification of a radioligand method [25]. The cut-off limit for IA-2A positivity was $0.43 \mathrm{RU}$, representing the $99^{\text {th }}$ percentile in a group of 374 healthy children and adolescents. The disease sensitivity was $62 \%$ and specificity $97 \%$ in 140 samples included in the Multiple Autoantibody Workshop [23].

Intravenous glucose tolerance tests. Intravenous glucose tolerance tests (IVGTTs) were carried out after seroconversion to ICA positivity in children who were one year of age or older. A standard protocol was closely followed [2]. The test began between 8:30 and 9:30 a.m. after overnight fasting. An intravenous cannula was inserted into a dorsal hand vein or antecubital vein after local anesthesia with lidocaine-prilocaine cream (EMLA, AstraZeneca, Södertälje, Sweden). The glucose dose, $0.5 \mathrm{~g}$ per $\mathrm{kg}$ body weight (maximum $35 \mathrm{~g}$ ), was infused through the cannula in $3 \mathrm{~min} \pm 15 \mathrm{~s}$. Blood for measuring serum glucose and insulin concentrations was drawn at 5 and 0 min before the start of the infusion, and at 1, 3, 5, and $10 \mathrm{~min}$ after the end of the infusion. Since only one intravenous cannula was used for both glucose infusion and sample drawing, meticulous care was taken to flush the line and the cannula properly with normal saline after the glucose infusion, and a $2.0 \mathrm{ml}$ discarded sample was drawn before the true sample. Serum insulin and glucose concentrations were measured using a standard radioimmunoassay and an enzymatic method, respectively. First-phase insulin response was calculated as the sum of serum insulin concentrations at 1 and 3 min. Firstphase insulin response values below $38 \mathrm{mU} / \mathrm{l}$ were regarded as decreased in this age group, representing the $5^{\text {th }}$ percentile of FPIRs in 20 healthy, ICA negative children under 5 years of age (Korhonen et al., unpublished). The area under the 0 to 10 min insulin curve (AUC) was also measured in all study children except two whose 10-min insulin concentrations were lacking.

The intravenous glucose tolerance tests of this study and the insulin analyses were carried out at two university hospital centres. The insulin assays in these two laboratories were compared by the parallel analysis of the same samples $(n=38)$ in both laboratories. The insulin values differed slightly between the two laboratories but correlated strongly $(r=0.97)$, and a regression transformation was done to make the values comparable.

Statistical analyses. Stepwise multiple regression analysis was applied to examine the dependence of FPIR and AUC (0-10 $\mathrm{min})$ from the age of the child at the time of IVGTT, the genetic risk group, number of positive autoantibody specificities, ICA titre $(<20 \mathrm{JDFU}$ or $\geq 20 \mathrm{JDFU})$, IAA positivity, GADA positivity and IA-2A positivity. Originally, the delay between the observed seroconversion and the first IVGTT was also included but the variable was omitted as the delay and the FPIR were not associated. Absolute FPIR and AUC values were replaced by rank numbers because the values showed a skewed distribution. Analyses were also carried out so that the dichotomous variables (positive or negative for a given antibody) were replaced by the actual titres or concentrations of the antibodies. In addition, multiple regression analysis was done without ICA to examine the additional effects of other autoantibodies on the FPIR values.

Differences between the groups were analysed using nonparametric Mann-Whitney U test, and correlation between the first and second FPIR was calculated using linear regression analysis. A chi-square test was used for the comparison of frequencies. Statistical analyses were done using the SAS (Version 6.1, Cary, NC, USA) and SPSS (Version 10.0 for Windows, Chicago, Ill., USA) software packages. A $p$ value of less than 0.05 was considered statistically significant.

\section{Results}

Altogether 52 IVGTTs were done in 48 index children and four at-risk siblings. The siblings had also seroconverted to ICA positivity during prospective followup, and accordingly the accurate time of seroconversion was known. They were also under 5 years of age at the time of the test, thus being comparable with the index children by both age and history of prediabetes.

Nine children had at least one additional IVGTT before randomization into the prevention trial or the diagnosis of clinical diabetes. The correlation $(r)$ between the first two tests carried out at 2.8 to 11.3 -month intervals was $0.87(p=0.002)$, suggesting that the intraindividual variation in the FPIR values is modest at this age (Fig. 1).

Of the 52 children who recently had seroconverted to ICA positivity, $22(42 \%)$ had a reduced FPIR in their first post-seroconversion IVGTT, as defined by a value under the $5_{\text {th }}$ percentile $(38 \mathrm{mU} / \mathrm{l})$ of FPIRs of 20 healthy children 1.3 to 4.9 years of age. Multiple regression analysis showed that ICA was an independent predictor of FPIR ( $p=0.0005)$, whereas the age of the child at the time of IVGTT and genetic risk group approached but failed to reach significance $(p=0.0681$ and $p=0.064$, respectively). The children $(n=26)$ with 


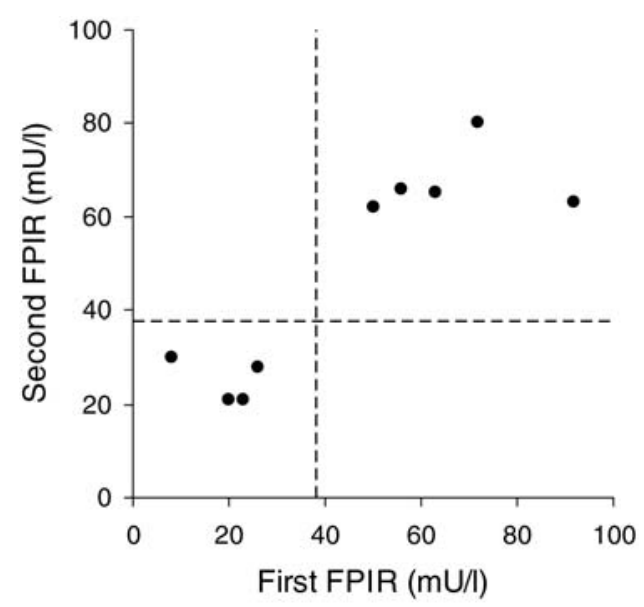

Fig. 1. Correlation between the first-phase insulin responses (FPIR) obtained in the first and the second intravenous glucose tolerance tests (IVGTT) carried out after seroconversion to autoantibody positivity. Nine children underwent two IVGTTs at intervals of 2.8-11.3 months. The FPIR from the first test is shown on the X-axis, and the FPIR from the second test on the Y-axis. $r=0.87 ; p=0.002$. Dashed lines indicate the lower limit of age-related normal range of FPIR, as defined by the $5^{\text {th }}$ percentile of FPIRs from 20 healthy children under 5 years of age $(38 \mathrm{mU} / \mathrm{l})$

ICA titres greater than or equal to $20 \mathrm{JDFU}$ had lower FPIRs (geometric mean $29 \mathrm{mU} / \mathrm{l}$, range 7-186 mU/l) than the children $(n=26)$ whose ICA was less than $20 \mathrm{JDFU}$ (59 mU/l; 8-258 mU/l; $p=0.001$ ) (Fig. 2). Of those with an ICA titre greater than or equal to 20 JDFU, 15 out of $26(58 \%)$ had a subnormal FPIR $(<38 \mathrm{mU} / \mathrm{l})$, whereas only seven $(27 \%)$ of those with a low ICA titre showed a reduced response $\left(\chi^{2}=5.04\right.$, $p=0.025$ ). If ICA was omitted in the multiregression analysis, IAA positivity was the most significant predictor of FPIR $(p=0.0009)$. Of those positive for IAA, 18 out of $31(58 \%)$ had a subnormal FPIR $(<38 \mathrm{mU} / \mathrm{l})$, and only four (19\%) of those negative for IAA showed a reduced response $\left(\chi^{2}=7.81, p=0.005\right)$.

If the actual autoantibody titres were used in the multiregression analysis instead of dichotomous variables (positivity or negativity for a given autoantibody), a low FPIR was associated with an increased number of positive autoantibody specificities $(p=0.001)$ and high titre of IAA $(p=0.049)$. First-phase insulin responses (geometric mean; range) declined with increasing number of positive autoantibody specificities (ICA only, $61 \mathrm{mU} / 1$; $26-218 \mathrm{mU} / \mathrm{l}$, one additional autoantibody $47 \mathrm{mU} / \mathrm{l} ; 22-97 \mathrm{mU} / \mathrm{l}$, two additional autoantibodies $38 \mathrm{mU} / \mathrm{l} ; 12-258 \mathrm{mU} / \mathrm{l}$, and three additional positive autoantibody specificities $25 \mathrm{mU} / \mathrm{l}$; 7-77 mU/l) (Fig. 3).

Of those 19 children who were positive only for ICA, four $(21 \%)$ had a subnormal FPIR, whereas 18 out of those 33 children positive for at least one additional antibody had a low response $\left(\chi^{2}=5.54\right.$, $p=0.019)$. The specificity of the other antibody in addition to ICA influenced the FPIR values only slight-

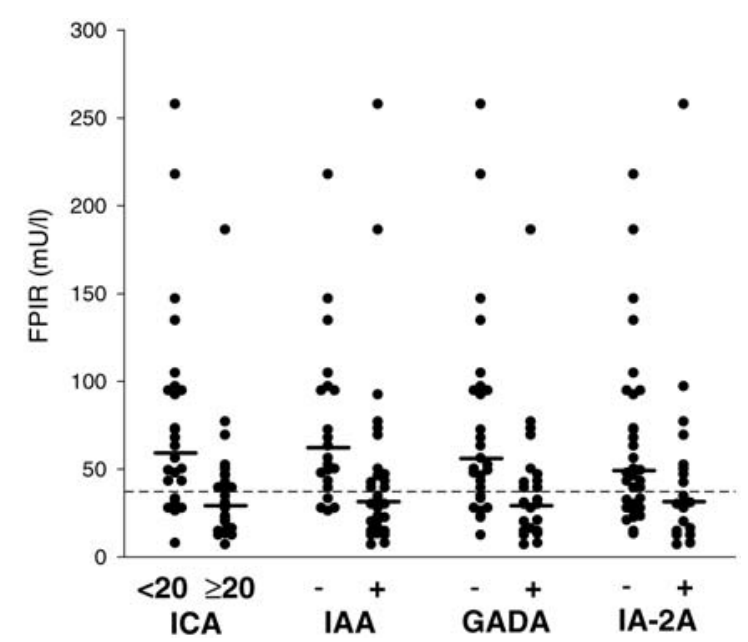

Fig. 2. The initial first-phase insulin responses in IVGTTs in children with different autoantibody status. The plots show individual responses. The FPIRs of the 52 children are shown according to the titre of the different autoantibodies: ICA either below or above 20 JDFU, IAA negative or positive, GADA negative or positive, and IA-2A negative or positive. Geometric means of the FPIR values are indicated by transverse bars. In paired comparisons of the groups (Mann-Whitney $\mathrm{U}$ test) the $p$ values for differences between mean FPIRs were 0.001 (ICA $<20$ or $\geq 20$ ), 0.001 (IAA negative or positive), 0.004 (GADA negative or positive) and 0.071 (IA-2A negative or positive). The dashed line indicates the lower limit of age-related normal range of FPIR, as defined by the $5^{\text {th }}$ percentile of FPIRs from 20 healthy children under 5 years of age $(38 \mathrm{mU} / \mathrm{l})$

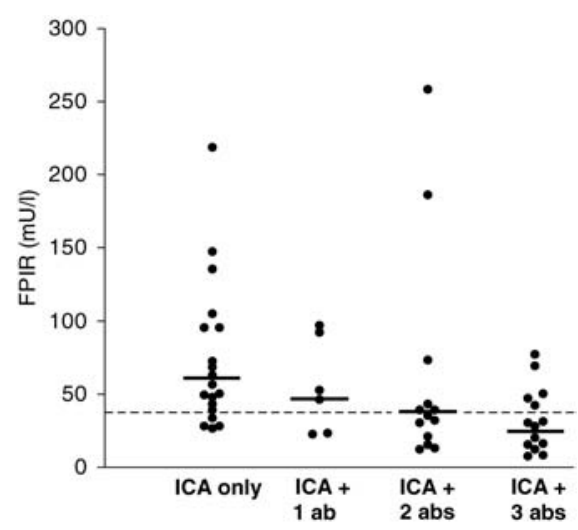

Fig. 3. First-phase insulin responses of children positive for ICA and one, two or three additional autoantibodies. Geometric means of the FPIR values are indicated by transverse bars. In paired comparisons of the groups (Mann-Whitney U test), mean FPIRs in children with only ICA and in those with four positive autoantibodies differed $(p=0.002)$. The dashed line indicates the lower limit of age-related normal range of FPIR, as defined by the $5^{\text {th }}$ percentile of FPIRs from 20 healthy children under 5 years of age $(38 \mathrm{mU} / \mathrm{l})$

ly. The geometric mean value (range) in children, who in addition to ICA were positive for IAA was 32 (7-258) mU/l, negative for IAA 62 (26-218) $\mathrm{mU} / \mathrm{l}$ $(p=0.001)$; positive for GADA $29(7-186) \mathrm{mU} / \mathrm{l}$, negative for GADA $56(12-258) \mathrm{mU} / \mathrm{l}(p=0.004)$; and in 
those positive and negative for IA-2A 31 (range 7-258) and 49 (range 13-218) $\mathrm{mU} / \mathrm{l}$, respectively $(p=0.071)$ (Fig. 2). Multiple regression analysis showed that positivity for GADA or IA-2A or their concentrations in serum were not independent predictors of FPIR, but related to ICA, IAA and the number of positive autoantibody specificities.

The most significant independent predictor of AUC (1-10 min) for serum insulin during IVGTT was ICA $(p=0.0002)$, as it was also the best predictor of FPIR. In addition, the child's age at the time of IVGTT and his or her genetic risk group reached significance in multiregression analysis $(p=0.045$ and 0.031 , respectively). The geometric mean of AUC $(0-10 \mathrm{~min})$ values of those with a moderate diabetes risk was $205 \mathrm{mU} / \mathrm{l}^{-1} \cdot 10 \cdot \mathrm{min}^{-1}$ (range 68-1005) and of those with a high risk $139 \mathrm{mU} / \mathrm{l}^{-1} \cdot 10 \cdot \mathrm{min}^{-1}$ (range 44-605) $(p=0.055$ for the difference between groups). The HLA-DQB1 risk genotype predicted the first post-seroconversion FPIR value poorly, although the values of moderate-risk children were slightly higher than those of the high-risk children (47; 8-258 $\mathrm{mU} / \mathrm{l}$ vs $32 ; 7-147 \mathrm{mU} / \mathrm{l}$, respectively; $p=0.095)$.

The children with high titres of ICA or positive for IAA were slightly younger at the time of detection of seroconversion and at the time of the IVGTT than children with low titres of ICA or negative for IAA (mean age \pm SD of those with high and low titres of ICA $1.6 \pm 1.1$ and $2.2 \pm 1.0$ years at the seroconversion, and $2.1 \pm 1.0$ and $2.8 \pm 1.0$ years at the first IVGTT, respectively, $p=0.005$ for both comparisons; mean age \pm SD of those positive and negative for IAA $1.6 \pm 1.0$ and $2.3 \pm 1.0$ years at the seroconversion, and $2.2 \pm 1.0$ and $2.9 \pm 1.1$ years at the first IVGTT, $p=0.011$ and 0.014 , respectively). The children with high titres of ICA or positive for IAA had also more positive autoantibody specificities (those with a high or low titre of ICA: median 3.5 antibodies vs 1 antibody, $p<0.001$, those positive or negative for IAA: median 3 antibodies vs 1 antibody, $p<0.001)$. Children with high titres of ICA were more often positive for any one of the other autoantibodies, as among these 26 children, $24(92 \%)$ were positive also for IAA, $19(73 \%)$ for GADA, and $16(62 \%)$ for IA-2A, while among the 26 children with low ICA titres only seven $(27 \%$, $\left.\chi^{2}=23.08, p<0.001\right)$, five $\left(19 \%, \chi^{2}=15.17, p<0.001\right)$ and three $\left(12 \%, \chi^{2}=14.02, p<0.001\right)$ subjects tested positive for the respective other autoantibodies. The proportion of children at high genetic risk was slightly higher among those with an ICA titre greater than or equal to $20 \mathrm{JDFU}$ ( $38 \%$ vs $27 \%, \chi^{2}=0.79, p=0.375$ ), and among those positive for IAA (39\% vs $24 \%$, $\chi^{2}=1.26, p=0.261$ ).

Five children positive for ICA only seroconverted back to ICA negativity after 1 to 4 samples taken at 3-month intervals. They all had low ICA titres, and their FPIRs did not differ from those children $(n=14)$

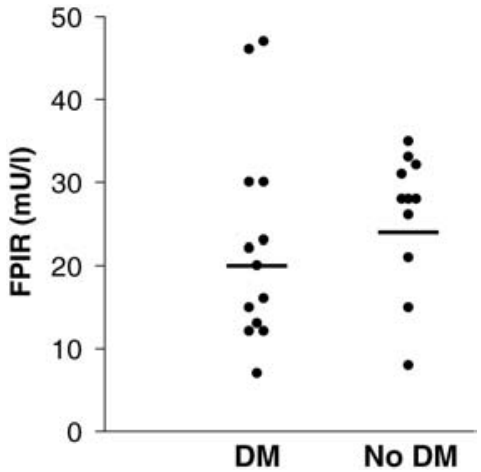

Fig. 4. First-phase insulin responses in children who developed clinical Type I diabetes by May 2001, and in lowresponders who were not diagnosed with the disease by that time. Geometric means of the FPIR values are indicated by transverse bars. The difference between the two groups did not reach significance $(p=0.209)$

who were also positive for ICA only but remained ICA positive in the follow-up (geometric mean for those positive for ICA only temporarily $62 \mathrm{mU} / \mathrm{l}$, range 43-95 mU/l, and $61 \mathrm{mU} / 1$ for those permanently ICA positive, range 26-218 mU/l).

Before 1st May 2001, 13 of the 52 study children (6 boys/7 girls) had developed clinical Type I diabetes at a mean age of 3.5 years (range $2.1-4.9$ years). The geometric mean of the first FPIRs of these children, 0.6 to 3.3 (mean 1.9) years before the diagnosis, was $20 \mathrm{mU} / \mathrm{l}$ (7 to $47 \mathrm{mU} / \mathrm{l}$ ) (Fig. 4). The initial FPIR of two children was within the normal range ( $\geq 38 \mathrm{mU} / \mathrm{l})$. Seroconversion to ICA positivity had occurred 2.2 $(1.0-3.5)$ years and seroconversion to any autoantibody positivity $2.4(1.2-3.8)$ years before the diagnosis. Of the 13 children two had a first-degree relative with Type I diabetes.

The children $(n=11)$ with a low FPIR $(<38 \mathrm{mU} / \mathrm{l})$ but no diabetes so far had a mean FPIR of $24 \mathrm{mU} / \mathrm{l}$ (geometric mean, range $8-35 \mathrm{mU} / \mathrm{l}$ ) in their first test ( $p=0.209$ for the difference between the mean FPIR in this group and in those who have developed diabetes) (Fig. 4). The follow-up of these non-progressors had on 1st May 2001 continued for 2.0 to 4.4 years (mean 2.9 years) after seroconversion to any autoantibody positivity, and for 1.5 to 4.4 years (mean 2.7 years) after seroconversion to ICA positivity. At the time of the first IVGTT, the children who later developed diabetes had a higher ICA titre (median 130 JDFU vs 18 JDFU, $p=0.005)$ and were more frequently positive for IAA $\left(100 \%\right.$ vs $\left.64 \%, \chi^{2}=5.67, p=0.017\right)$ than those who so far have remained non-diabetic. The number of positive autoantibody specifities (median 4 vs 3 in those with and without diabetes, respectively, $p=0.150$ ), the frequency of GADA positivity (69\% vs $\left.55 \%, \chi^{2}=0.55, p=0.459\right)$ or the frequency of IA-2A positivity $\left(62 \%\right.$ vs $\left.36 \%, \chi^{2}=1.51, p=0.219\right)$ did not differ between the two groups at that time point. The high-risk genotype was not more frequent among the 

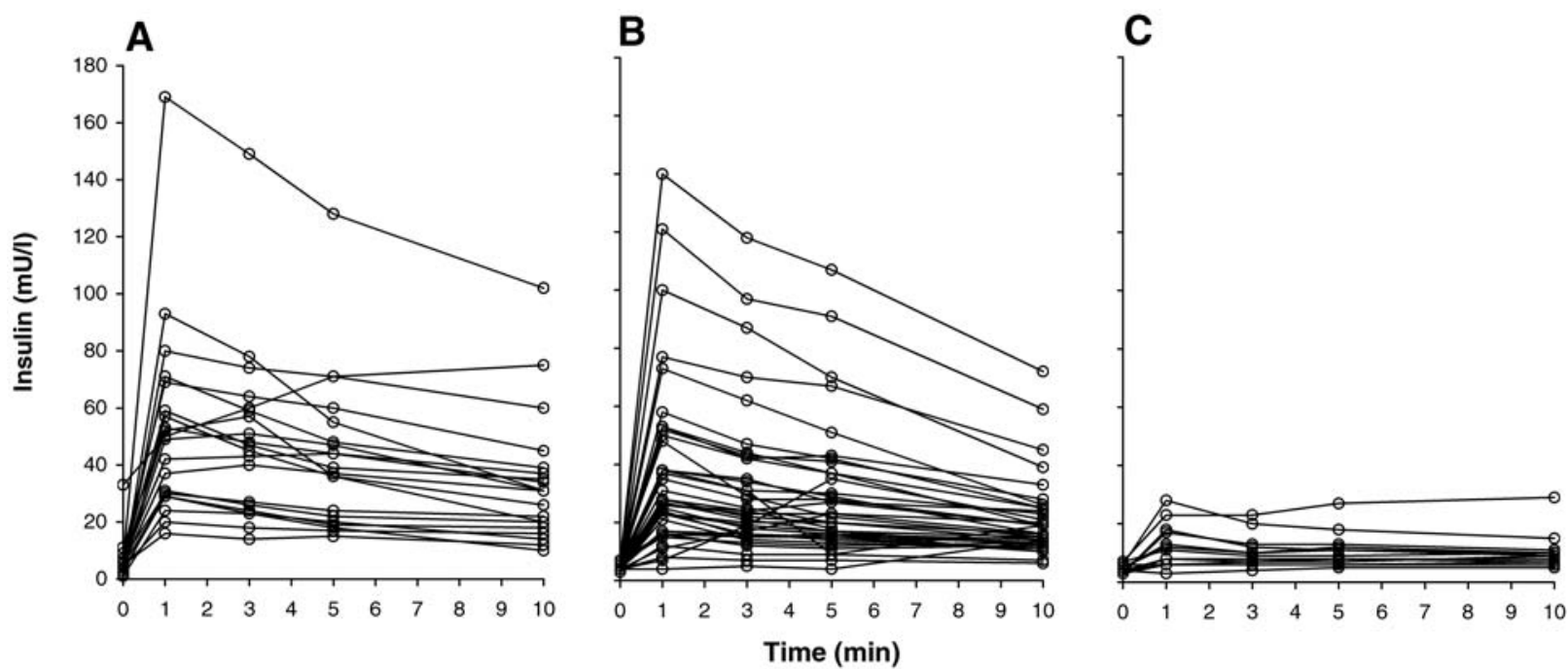

Fig. 5A-C. Individual insulin concentrations during IVGTTs performed to A ICA negative children 1-5 years of age, B ICA positive children who had not progressed to diabetes by May 2001, and C ICA positive children who had developed clinical Type I diabetes by May 2001

progressors than among those without the disease (38\% in those with vs $45 \%$ in those without diabetes, $\chi^{2}=0.12, p=0.729$ ). Insulin concentrations of individual children at each time point during the 10-min IVGTT are shown in Figure 5.

\section{Discussion}

Decreased FPIR has been regarded as an indicator of advanced beta-cell destruction, i.e., late prediabetes $[3,5,6,7,8,9]$. This study shows that very low FPIRs are common shortly after seroconversion to autoantibody positivity in young children with HLA-DQB1associated genetic risk for Type I diabetes and isletcell antibodies. The finding might suggest that in young children the autoimmune-mediated destruction of beta cells occurs early in the course of prediabetes, as previously assumed $[3,26]$, but in our series of prospectively observed children a number of individuals have remained non-diabetic for a relatively long time period despite very low FPIRs. Our findings raise the issue of metabolic compensation mechanisms, e.g., changes in insulin sensitivity, that could alter disease progression so that the child remains normoglycaemic for a considerable period of time in spite of minimal FPIRs. Also, the very early attenuation of FPIR might suggest the possibility of beta-cell failure preceding detectable autoantibody positivity. It has been reported earlier that ICA negative siblings of diabetic children could have abnormally low FPIRs, suggesting an intrinsic, non-immune mediated defect of insulin secretion in these children [27]; however, other autoantibodies were not measured in that study.
First-phase insulin responses were attenuated early especially in the children with high ICA titres, and in children positive for IAA or multiple autoantibodies. The association between low FPIRs and high ICA titres, reported earlier in close relatives of patients with Type I diabetes [13, 14], suggests that conspicuous amounts of antigens are most likely released during beta-cell destruction, resulting in a strong humoral immune response. Despite the fact that the mechanisms of decline in the functional secretory capacity of the beta cells remain speculative, ICA titres could to some extent be used as indicators of the stage of impairment of insulin-secretory capacity of the beta cells [13]. High ICA titres are associated with an increased risk of Type I diabetes; it has been suggested that this could be due to the usual association of high titres of ICA with autoantibodies to GAD and IA-2 [28]. In our study children with high ICA titres were more often positive for IAA, GADA, IA-2A and multiple autoantibodies than those with low ICA titres. However, GADA and IA-2A failed to independently predict FPIR but were linked with a high ICA, IAA or positivity for multiple autoantibodies. Controversial results have been reported on the association of IAA and FPIR in relatives of patients with Type I diabetes. In a sub-study of DPT-1, low FPIRs were observed in subjects with high titres of IAA [14], whereas in a Finnish study such an association was not observed [13]. In this study, the first FPIR values were lower in children with a higher number of detectable autoantibodies, a phenomenon possibly reflecting rapid epitope spreading from one to multiple beta-cell antigens in these children. An association between positivity for multiple autoantibody specificities and a low FPIR was also observed in a cohort of schoolchildren, representing non-familial Type I prediabetes [29]. In that series no association could be detected between ICA and FPIR, whereas positivity for IAA was associated with a low FPIR. The wide variations in results obtained in studies on the relationship between different variables of diabetes-related autoimmunity and meta- 
bolic markers such as FPIR suggest that the predictive value of each variable could depend on the study cohort (age, familial vs sporadic Type I diabetes mellitus etc.).

Reference ranges of FPIR in healthy young children are poorly defined. It has been reported that FPIR increases with age, especially during puberty when insulin sensitivity is decreased [12, 27, 30, 31]. However, only a few children less than 5 years old have been included in these studies. In this study, the children with multiple autoantibody specificities and high autoantibody titres were slightly younger than those with ICA only or those with a low ICA titre. The age range in our study was, however, rather narrow (1-5 years), and the age was not found to be an independent predictor of FPIR within this group.

In earlier studies, the association between the HLA-DQB1 genotype and FPIR has been controversial. Among ICA positive siblings of children recently diagnosed with Type I diabetes the high-risk genotype HLA-DQB $1 * 02 / * 0302$ is associated with a low FPIR [13]. However, no association between a diminished FPIR and high-risk HLA-DQB1 genotype was observed in a group of ICA positive schoolchildren, all comprising non-familial cases of prediabetes [29]. In this study representing mostly also non-familial prediabetes, the HLA-DQB1 genotype was not an independent predictor of FPIR, but seemed to predict the AUC(1-10 min) for insulin during the 10-minute IVGTT. As mentioned above, it has been reported earlier that ICA negative siblings of diabetic children could have abnormally low FPIRs [27]. However, as in that study only ICA was measured, children with low FPIRs could have had other diabetes-associated autoantibodies. Autoantibody negative children with an HLA-DQB1 -conferred diabetes risk would probably represent the most suitable control group for the autoantibody positive risk children of this study. Before such analyses become available, an intrinsic, nonautoimmune mediated defect of beta-cell function in those with risk HLA-DQB1 genotypes remains a possibility.

The value of FPIR in the prediction of Type I diabetes has been questioned. Doubts have been raised concerning the sensitivity, specificity, reproducibility and predictive value of the methodology $[5,6,7,11$, 12]. The extent to which FPIR reflects the rate of beta-cell destruction and predicts the time of onset of Type I diabetes is still a matter of controversy. In the earlier studies wide age ranges of the study subjects, relatively short follow-up times, and unknown history of the subjects' seropositivity have complicated meaningful interpretation of the results. In those previous studies the prediabetic subjects have been seropositive for autoantibodies for an unknown period of time prior to the first IVGTT, since seropositivity has usually been an inclusion criteria for follow-up. Longitudinal studies with long follow-up times, large cohorts of study subjects, and frequently repeated tests are obviously needed to evaluate the usefulness of FPIR in diabetes prediction. The importance of follow-up is highlighted also by the fact that several cross-sectional studies in older subjects have shown no differences in the FPIRs between ICA positive and negative subjects, but later the FPIRs of the ICA positive subjects have decreased [12].

In this study, we assessed beta-cell function close to the initiation of recognisable beta-cell autoimmunity. It has been assumed that the cascade of autoimmune events leading to Type I diabetes later possibly starts early in life, perhaps before the age of 6 years [32]. Most children in the DIPP follow-up were recruited into the double-blind intervention study by the time of the second IVGTT. Since the test treatment (intranasal insulin) could affect the FPIR values, thorough analysis of our longitudinal follow-up data becomes possible only when the double-blinded prevention trial has been completed.

It is difficult to accurately catch the very moment of seroconversion to autoantibody positivity for assessment of beta-cell function at the time of emergence of autoantibodies, but our approach probably represents the earliest possible post-seroconversion stage, although two limitations have to be kept in mind. Firstly, we use ICA as the primary marker of beta-cell autoimmunity, and measure other autoantibodies only if ICA has been detected. In our cohort like in others [33, 34] IAA is most often the firstemerging autoantibody in young children, and thus the autoimmune processes could have continued for some time at the time of seroconversion to ICA positivity. However, this delay in timing is probably minimal, as we recently showed that the autoantibodies usually emerge within a short time window in those young children who develop multiple autoantibodies [34]. Secondly, the follow-up interval was either 3 or 6 months before the age of 2 years, and 6 or 12 months after the age of 2 years; thus, if the seroconversion occurs immediately after the previous sample, the interval between the true and observed seroconversion could maximally lengthen to almost one year. Furthermore, occasionally a follow-up visit is skipped by the family, which naturally causes a longer follow-up interval than planned.

Of the children in this study thirteen developed clinical Type I diabetes by 1st May 2001. Of them eleven had a low FPIR in their first IVGTT. At the time of the test, they had higher ICA titres than the children with low FPIRs but no diabetes during follow-up. The group of children in the DIPP project with diabetes is, however, still too small to allow the assessment of the predictive characteristics for the various variables, such as FPIR, observed close to the time of seroconversion.

Our data show that a reduced FPIR is present in about $40 \%$ of young children with increased genetic 
susceptibility to Type I diabetes close to the first sample positive for ICA indicating that insulin secretory capacity could be decreased early in the course of preclinical diabetes in such individuals. High initial ICA and IAA titres and positivity for multiple autoantibodies were predictors of a reduced FPIR. Repeated IVGTTs in nine children suggest that the reproducibility of the FPIR is relatively high with no observed conversion from a reduced response to a normal response and vice versa between the two test occasions. Some children with a conspicuously impaired FPIR initially have remained non-diabetic for several years. This indicates that the insulin response to stimuli other than glucose has remained normal or that insulin sensitivity is increased in these children.

Acknowledgements. The study was financially supported by Juvenile Diabetes Research Foundation International (grants 4-1998-274, 197032 and 4-1999-731), Foundation for Pediatric Research, Finland, Sigrid Juselius Foundation, Academy of Finland, Päivikki and Sakari Sohlberg Foundation, Novo Nordisk Foundation, Foundation for Diabetes Research, Finland, Signe and Ane Gyllenberg Foundation, and Special Grants for the University Hospitals of Turku and Oulu. The numerous Finnish families participating in the DIPP study are gratefully acknowledged for their dedication. J. Hakalax provided superb help with statistical analyses. H. Haapanen, E. HoppendorfKoskinen, H. Lusto, B. Nurmi, L.-M. Nuutila, H. Pohjola, K.-L. Rasimus, K. Riikonen, A. Stenius and M. Törmä are thankfully acknowledged for good care of DIPP children and for practical carry-out of IVGTTs; H. Kukkula, E. Mäntymäki, M. Romo, R. Sihvo and A. Suutari for excellent sampletaking; and S. Anttila, S. Heikkilä, M. Karlsson, T. Laurén, T. Mehtälä, R. Päkkilä, P. Salmijärvi and R. Suominen for analyses of genotypes, autoantibodies and insulin.

\section{References}

1. Daniel S, Noda M, Straub SG, Sharp GW (1999) Identification of the docked granule pool responsible for the first phase of glucose-stimulated insulin secretion. Diabetes 48:1686-1690

2. Bingley PJ, Colman P, Eisenbarth GS et al. (1992) Standardization of IVGTT to predict IDDM. Diabetes Care 15:1313-1316

3. Bingley PJ (1996) Interactions of age, islet cell antibodies, insulin autoantibodies, and first-phase insulin response in predicting risk of progression to IDDM in ICA+ relatives: the ICARUS data set. Islet Cell Antibody Registers Users Study. Diabetes 45:1720-1728

4. Ganda OP, Srikanta S, Brink SJ et al. (1984) Differential sensitivity to beta-cell secretagogues in "early" type I diabetes mellitus. Diabetes 33:516-521

5. Srikanta S, Ganda OP, Gleason RE, Jackson RA, Soeldner JS, Eisenbarth GS (1984) Pre-type 1 diabetes. Linear loss of beta cell response to intravenous glucose. Diabetes 33:717-720

6. Vialettes B, Mattei-Zevaco C, Badier C, Ramahandridona G, Lassman-Vague V, Vague P (1988) Low acute insulin response to intravenous glucose. A sensitive but non-specific marker of early stages of Type I (insulin-dependent) diabetes. Diabetologia 31:592-596
7. Vardi P, Crisa L, Jackson RA (1991) Predictive value of intravenous glucose tolerance test insulin secretion less than or greater than the first percentile in islet cell antibody positive relatives of Type I (insulin-dependent) diabetic patients. Diabetologia 34:93-102

8. Herskowitz-Dumont R, Wolfsdorf JI, Jackson RA, Eisenbarth GS (1993) Distinction between transient hyperglycemia and early insulin-dependent diabetes mellitus in childhood: a prospective study of incidence and prognostic factors. J Pediatr 123:347-354

9. Greenbaum CJ, Sears KL, Kahn SE, Palmer JP (1999) Relationship of beta-cell function and autoantibodies to progression and nonprogression of subclinical type 1 diabetes: follow-up of the Seattle Family Study. Diabetes 48:170-175

10. Bardet S, Pasqual C, Maugendre D, Remy JP, Charbonnel B, Sai P (1989) Inter and intra individual variability of acute insulin response during intravenous glucose tolerance tests. Diabetes Metab 15:224-232

11. Bleich D, Jackson RA, Soeldner JS, Eisenbarth GS (1990) Analysis of metabolic progression to type 1 diabetes in $\mathrm{ICA}^{+}$relatives of patients with type 1 diabetes. Diabetes Care 13:111-118

12. Robert J-J, Deschamps I, Chevenne D, Roger M, Mogenet A, Boitard C (1991) Relationship between first-phase insulin secretion and age, HLA, islet cell antibody status, and development of type 1 diabetes in 220 juvenile first-degree relatives of diabetic patients. Diabetes Care 14:718-723

13. Veijola R, Vähäsalo P, Tuomilehto-Wolf E et al. (1995) Human leukocyte antigen identity and DQ risk alleles in autoantibody-positive siblings of children with IDDM are associated with reduced early insulin response. Diabetes 44:1021-1028

14. Chase HP, Cuthbertson DD, Dolan LM et al. (2001) Firstphase insulin release during the intravenous glucose tolerance test as a risk factor for type 1 diabetes. J Pediatr 138:244-249

15. Hahl J, Simell T, Ilonen J, Knip M, Simell O (1998) Costs of predicting IDDM. Diabetologia 41:79-85

16. Kupila A, Muona P, Simell T et al. (2001) Feasibility of genetic and immunological prediction of Type I diabetes in a population-based birth cohort. Diabetologia 44:290297

17. Nejentsev S, Sjöroos M, Soukka T et al. (1999) Populationbased genetic screening for the estimation of type 1 diabetes mellitus risk in Finland: selective genotyping of markers in the HLA-DQB1, HLA-DQA1 and HLA-DRB1 loci. Diabet Med 16:985-992

18. Sjöroos M, Iitiä A, Ilonen J, Reijonen H, Lövgren T (1995) Triple-label hybridization assay for type-1 diabetes-related HLA alleles. Biotechniques 18:870-877

19. Knip M, Karjalainen J, Åkerblom HK, and the Childhood Diabetes in Finland Study Group (1998) Islet cell antibodies are less predictive of IDDM among unaffected children in the general population than in sibs of children with diabetes. Diabetes Care 21:1670-1673

20. Bottazzo GF, Florin-Christensen A, Doniach D (1974) Islet-cell antibodies in diabetes mellitus with autoimmune polyendocrine deficiencies. Lancet ii:1279-1283

21. Williams AJ, Bingley PJ, Bonifacio E, Palmer JP, Gale EAM (1997) A novel micro-assay for insulin autoantibodies. J Autoimmun 10:473-478

22. Ronkainen M, Hämälàinen A-M, Koskela P, Åkerblom HK, Knip M (2001) Pregnancy induces nonimmunoglobulin insulin-binding activity in both maternal and cord blood serum. Clin Exp Immunol 124:190-196 
23. Verge CF, Stenger D, Bonifacio E et al. (1998) Combined use of autoantibodies (IA-2 autoantibody, GAD autoantibody, insulin autoantibody, cytoplasmic islet cell antibodies) in type 1 diabetes: Combinatorial islet antibody workshop. Diabetes 47:1857-1866

24. Savola K, Sabbah E, Kulmala P, Vahasalo P, Ilonen J, Knip M (1998) Autoantibodies associated with Type I diabetes mellitus persist after diagnosis in children. Diabetologia 41:1293-1297

25. Savola K, Bonifacio E, Sabbah E et al. (1998) IA-2 antibodies - a sensitive marker of IDDM with clinical onset in children and adolescents. Diabetologia 41:424-429

26. Riley WJ, Maclaren NK, Krischer J et al. (1990) A prospective study of the development of diabetes in relatives of patients with insulin-dependent diabetes. N Engl J Med 323:1167-1172

27. Carel JC, Boitard C, Bougneres PF (1993) Decreased insulin response to glucose in islet cell antibody-negative siblings of type 1 diabetic children. J Clin Invest 92:509513

28. Maclaren N, Lan M, Coutant R et al. (1999) Only multiple autoantibodies to islet cells (ICA), insulin, GAD65, IA-2 and IA-2 $\beta$ predict immune-mediated (type 1) diabetes in relatives. J Autoimmun 12:279-287
29. Kulmala P, Rahko J, Savola K et al. (2000) Stability of autoantibodies and their relation to genetic and metabolic markers of Type 1 diabetes in initially unaffected schoolchildren. Diabetologia 43:457-464

30. Allen HF, Jeffers BW, Klingensmith GJ, Chase HP (1993) First-phase insulin release in normal children. J Pediatr 123:733-738

31. Lorini R, Vanelli M, and the Prediabetes Study Group of the Italian Society for Pediatric Endocrinology and Diabetology (SIEDP) (1996) Normal values of first-phase insulin response to intravenous glucose in healthy Italian children and adolescents. J Pediatr Endocrinol Metab 9:163-167

32. Leslie RD, Elliott RB (1994) Early environmental events as a cause of IDDM. Evidence and implications. Diabetes 43:843-850

33. Ziegler AG, Hummel M, Schenker M, Bonifacio E (1999) Autoantibody appearance and risk for development of childhood diabetes in offspring of parents with type 1 diabetes: the 2-year analysis of the German BABYDIAB Study. Diabetes 48:460-468

34. Kupila A, Keskinen P, Simell T et al. (2002) Genetic risk determines the emergence of diabetes-associated autoantibodies in young children. Diabetes 51:646-651 